\title{
Pengaruh Progressive Muscle Relaxation Terhadap Respon Stres, Kadar Glukosa Darah, dan Kualitas Hidup pada Pasien Diabetes Melitus: A Systematic Review
}

\author{
Ida Trisnawati \\ Fakultas Keperawatan, Universitas Airlangga; ida.trisnawati-2018@ fkp.unair.ac.id (koresponden) \\ Novita Fajriyah \\ Fakultas Keperawatan, Universitas Airlangga; novita.fajriyah-2018@ fkp.unair.ac.id \\ Wahyu Sukma Samudera \\ Fakultas Keperawatan, Universitas Airlangga Surabaya; wahyu.sukma.samudera-2018@fkp.unair.ac.id
}

\begin{abstract}
Background: Various complications caused by causing diabetes mellitus patients to undergo treatment at the Hospital to overcome the complaints that arise. This causes the patient to experience stress physically and psychologically. Objective: To explain the effect of progressive muscle relaxation on the stress response, blood glucose levels, and quality of life in patients with diabetes mellitus. Method: This systematic review used the PRISMA approach. The database used in this study were Scopus, Pubmed, Proquest, and Science Direct in English. Results: Progressive Muscle Relaxation $(P M R)$ could reduce muscle tension, stress, lower blood pressure, increased tolerance for daily activities. Regular exercise can make it easier for patients to concentrate and relax conditions will be more quickly achieved thereby increasing the performance of the adrenal glands to produced sedative hormones which will have an impact on reducing stress and decreasing blood glucose levels so that the quality of life of DM patients increased. Conclusion: PMR influences the stress response, blood glucose levels, and quality of life in patients with diabetes mellitus.
\end{abstract}

Keywords: progressive muscle relaxation; stress; blood glucose level; quality of life; diabetes mellitus

\section{ABSTRAK}

Latar belakang: Berbagai komplikasi yang ditimbulkan menyebabkan pasien diabetes mellitus harus menjalani perawatan di Rumah Sakit untuk mengatasi keluhan yang ditimbulkan. Hal ini menyebabkan pasien mengalami stres secara fisik maupun secara psikologis. Tujuan: Untuk menjelaskan pengaruh progressive muscle relaxation terhadap respon stres, kadar glukosa darah dan kualitas hidup pada pasien Diabetes Melitus. Metode: Systematic review ini menggunakan pendekatan PRISMA. Database yang digunakan adalah Scopus, Pubmed, Proquest, dan Science Direct menggunakan bahasa Inggris. Hasil: Progressive Muscle Relaxation (PMR) mampu mengurangi ketegangan otot, menurunkan stress, menurunkan tekanan darah, meningkatkan toleransi terhadap aktivitas sehari-hari. Latihan yang teratur dapat membuat pasien lebih mudah untuk memusatkan pikiran dan kondisi rileks akan lebih cepat tercapai sehingga meningkatkan kinerja kelenjar adrenal untuk memproduksi hormon penenang yang akan berdampak pada penurunan stres dan penurunan kadar glukosa darah sehingga kualitas hidup pasien DM meningkat. Kesimpulan: PMR memiliki pengaruh terhadap respon stres, kadar glukosa darah, dan kualitas hidup pada pada pasien diabetes melitus.

Kata kunci: progressive muscle relaxation; stres; kadar glukosa darah; kualitas hidup; diabetes melitus

\section{PENDAHULUAN}

Diabetes Melitus (DM) merupakan suatu kelompok penyakit metabolik dengan karakteristik hiperglikemia yang terjadi karena kelainan sekresi insulin, kerja insulin atau kedua-duanya ${ }^{(1)}$. Hiperglikemia atau peningkatan kadar gula darah dalam tubuh yang tidak ditangani dengan baik dalam rentang waktu yang cukup lama dapat menyebabkan komplikasi seperti retinopathy, microangiopathy, dan gangrene ${ }^{(2)}$. Berbagai komplikasi yang ditimbulkan menyebabkan pasien harus menjalani perawatan di Rumah Sakit untuk mengontrol kadar glukosa darah dan keluhan yang ditimbulkan dari komplikasi tersebut. Keadaan seperti ini dapat membuat pasien DM mengalami stres secara fisik maupun secara psikologis sehingga menyebabkan peningkatan kadar glukosa darah ${ }^{(3)}$. Pasien yang menderita DM tingkat stressnya meningkat berkisar 20-40\%(4). Badan Kesehatan Dunia (WHO) memprediksi kenaikan jumlah penyandang DM di Indonesia dari 8,4 juta pada tahun 2000 menjadi sekitar 21,3 juta pada tahun 2030. Hal tersebut menunjukkan bahwa adanya peningkatan jumlah penyandang DM sebanyak 2-3 kali lipat pada tahun 2035. International Diabetes Federation (IDF) memprediksi adanya kenaikan jumlah penyandang DM di Indonesia dari 9,1 juta pada tahun 2014 menjadi 14,1 juta pada tahun $2035^{(1)}$.

Pasien DM yang mengalami stres maupun kecemasan menjadi salah satu faktor pemicu terjadinya peningkatan kadar glukosa darah. Respon stres merupakan bagian dari jalur umpan balik yang tertutup antara otot-otot dan pikiran ${ }^{(5)}$. Kondisi pasien yang mengalami stres akan mengaktifkan system neuroendokrin dan system saraf simpatis melalui hipotalamus pituitari-adrenal sehingga menyebabkan pelepasan hormon-hormon seperti epinefrin, kortisol, glukagon, ACT, kortikosteroid, dan tiroid sehingga dapat mempengaruhi kadar glukosa darah dalam tubuh. Selain itu peningkatan kadar glukosa darah juga dipengaruhi oleh faktor perawatan diri yang buruk seperti pola makan yang tidak sesuai dengan 3J (jadwal makan, jumlah yang dimakan dan jenis makanan yang dikonsumsi), rendahnya latihan jasmani, dan penggunaan obat-obatan yang tidak teratur ${ }^{(6)}$. 
Pengelolaan DM membutuhkan waktu yang lama dan terus-menerus. Hal ini bertujuan agar tidak menimbulkan komplikasi menjadi penyakit lain dengan menerapkan empat pilar penanganan diabetes melitus diantaranya edukasi, terapi nutrisi medis (TNM), terapi farmakologis, dan latihan jasmani ${ }^{(1)}$. Latihan jasmani dengan relaksasi yang dapat diterapkan pada pasien DM diantaranya dengan Progressive Muscle Relaxation (PMR) ${ }^{(7)}$. Gerakan pada latihan ini bertujuan untuk mengencangkan dan melemaskan otot-otot pada satu bagian tubuh pada satu waktu untuk memberikan perasaan relaksasi secara fisik ${ }^{(5)}$. Relaksasi dapat menenangkan sistem syaraf sehingga membuat tubuh penderita menjadi rileks ${ }^{(8)}$. Latihan ini memiliki kelebihan diantaranya tidak membutuhkan biaya yg mahal, mudah untuk dilakukan secara mandiri serta memiliki keunggulan dalam menahan respon stres dengan mencoba meredakan ketegangan otot secara $\operatorname{sadar}^{(9)}$.

Tujuan dari systematic review ini adalah untuk menjelaskan pengaruh progressive muscle relaxation terhadap respon stres, kadar glukosa darah dan kualitas hidup pada pasien Diabetes Melitus.

\section{METODE}

Systematic review ini disusun berdasarkan Preferred Reporting Items for Systematic Reviews and MetaAnalyzes (PRISMA).

Proses pencarian artikel dilakukan pada bulan Oktober sampai dengan Desember 2019. Strategi pencarian artikel dilakukan dengan menggunakan database dari Scopus, Pubmed, Proquest, dan Science Direct. Pencarian artikel dilakukan secara sistematis dengan menggunakan bahasa Inggris dari tahun 2014 sampai 2019. Kata kunci yang digunakan dalam pencarian adalah "Progressive Muscle Relaxation", "Relaxation Technique", dan "Diabetes Mellitus" untuk mencari artikel yang relevan. Dalam pencarian artikel menggunakan "AND". Pencarian referensi di Google Schoolar pada semua bidang untuk memfilter referensi yang diambil. Hal ini bertujuan sebagai strategi pencarian cukup luas untuk mendapatkan semua studi secara potensial dan relevan untuk ditinjau. Peneliti menyaring teks lengkap dari referensi yang dipilih tanpa terkecuali berdasarkan judul dan abstrak. Hal ini bertujuan untuk mendapatkan artikel sebanyak mungkin dan bersifat relevan.

Kriteria inklusi pada systematic review ini adalah 1) Artikel yang berfokus pada intervensi Progressive Muscle Relaxation atau Relaxation Technique, 2) Partisipan adalah pasien diabetes melitus, 3) Artikel diterbitkan dalam bahasa Inggris, 4) Seleksi artikel tidak dibatasi oleh kualitas metodologis, populasi dan hasil. Kriteria eksklusi dalam systematic review ini adalah: 1) Penelitian yangdilakukan selain pada pasien diabetes melitus, 2) Penelitian yang tidak dipublikasikan termasuk tesis, disertasi, abstrak konferensi dan laporan kasus.

Artikel yang diperoleh dari Scopus, Pubmed, Proquest, dan Science Direct diseleksi sesuai dengan kriteria yang telah ditetapkan dan menghapus artikel yang sama. Peneliti mengekstraksi data yang berisi tentang 1) Judul artikel, 2) penulis artikel, 3) tahun publikasi, 4) negara studi, 5) waktu yang dibutuhkan selama penelitian, 6) Sampel penelitian, 7) karakteristik populasi yang dijadikan penelitian, 8) variabel yang diteliti, 9) karakteristik intervensi dan hasil serta memeriksa keakuratan hasil ekstraksi data.

\section{HASIL}

Hasil pencarian studi literatur awal ditemukan sebanyak 246 artikel (24 dari Scopus, 18 dari Pubmed, 178 dari Proquest, dan 26 dari Science Direct). Artikel tersebut diidentifikasi sesuai dengan kriteria yang telah ditetapkan dan menghapus artikel yang sama. Ada7 artikel telah diidentifikasi secara sistematis dalam pencarian database elektronik dan memenuhi kriteria inklusi. Desain penelitian yang digunakan terdiri dari 4 artikel yang menggunakan randomized clinical trial dan 3 artikel yang menggunakan quasi experiment. Artikel diterbitkan dalam bahasa inggris. Studi dilakukan dalam berbagai negara seperti Iran, Indonesia, Abu Dhabi, China, Yunani dan Jepang.

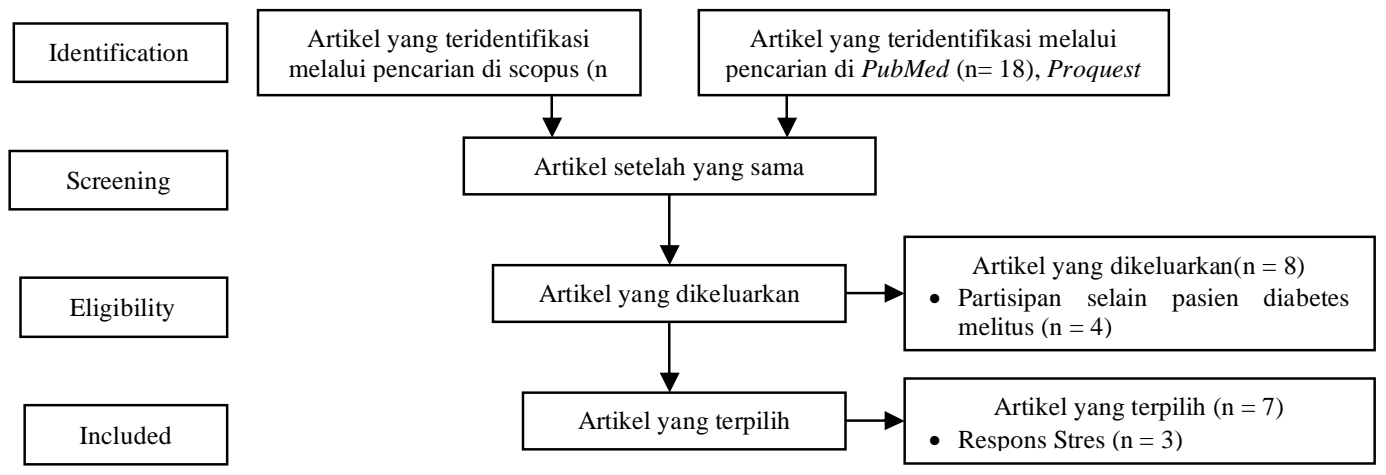

Gambar 1. Diagram flow dan pemilihan artikel

Jumlah pasien yang terlibat dalam penelitian tersebut sebanyak 473 pasien. Pasien DM tipe 2 secara acak dibagi menjadi 2 kelompok yaitu kelompok kontrol dan kelompok perlakuan. Adapun penelitian yang dilakukan dengan membagi pasien DM menjadi 3 kelompok : Grup MM (meditasi mindfulness), Grup CM (kontrol meditasi), dan Grup PM (meditasi relaksasi progresif) ${ }^{(10)}$. Hasil pengukuran dari studi yang dipilih bertujuan untuk menilai pengaruh PMR 
terhadap respon stres, kadar glukosa darah dan kualitas hidup pada pasien DM. Variabel indikator yang diukur meliputi kualitas Hidup Diabetes Diabetes Iran (IDQoL-BCI) ${ }^{(11)}$, kadar HbA1c ${ }^{(11),(12),(13),(14)}$, nyeri neuropati perifer(BPI-DPN Q4) ${ }^{(10)}$, skor depresi pada pasien $\mathrm{DM}^{(12),(13)}$, skor ansietas pada pasien $\mathrm{DM}^{(12)}$, Perubahan konsentrasi amilase saliva ${ }^{(14)}$, perubahan tekanan darah ${ }^{(14),(15)}$, perubahan denyut jantung ${ }^{(14)}$, skala perilaku koping $^{(14)}$, pola kesehatan mental ${ }^{(14)}$, dan kadar glukosa darah saat puasa dan 2 jam postprandial ${ }^{(15)}$.

Tabel 1. Pengaruh progressive muscle relaxation pada pasien diabetes melitus

\begin{tabular}{|c|c|c|c|c|c|}
\hline No & Judul dan Penulis & $\begin{array}{c}\text { Negara, Desain studi } \\
\text { dan Populasi }\end{array}$ & $\begin{array}{c}\text { Desain } \\
\text { Penelitian }\end{array}$ & Variabel & Hasil \\
\hline 1 & \begin{tabular}{|l|} 
The effect of progressive \\
muscle relaxation on \\
glycated hemoglobin and \\
health-related quality of \\
life in patients with type 2 \\
diabetes mellitus ${ }^{(11)}$
\end{tabular} & $\begin{array}{l}\text { Iran, } 65 \text { pasien dengan } \\
\text { DM tipe } 2 \text { secara acak } \\
\text { dibagi } r \text { menjadi } \\
\text { kelompok kontrol }(\mathrm{n}= \\
\text { 35) dan PMR }(\mathrm{n}=30)\end{array}$ & $\begin{array}{l}\text { Randomized } \\
\text { Clinical Trial }\end{array}$ & $\begin{array}{l}\text { Kualitas rr Hidup } \\
\text { Diabetes Diabetes } \\
\text { Iran (IDQoL-BCI); } \\
\text { kadar HbA1c }\end{array}$ & $\begin{array}{l}\text { Pada kelompok PMR terjadi penurunan } \\
\text { yang signifikan dalam kadar HbA1c }(\mathrm{P}= \\
0,04) \text { dan peningkatan yang signifikan } \\
\text { dalam skor total HRQoL }(\mathrm{P}=0,045) \text { dan } \\
\text { dimensi psikososialnya }(\mathrm{P}=0,019) \text {. }\end{array}$ \\
\hline 2 & 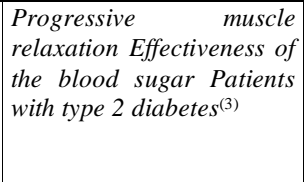 & $\begin{array}{l}\text { Indonesia, } 48 \text { pasien } \\
\text { secara acak dibagi } \\
\text { menjadi } \\
\text { kontrol }(\mathrm{n}=24) \text { dan } \\
\text { kelompok perlakuan }(\mathrm{n} \\
=24) .\end{array}$ & $\begin{array}{l}\text { Randomized } \\
\text { Clinical Trial }\end{array}$ & Kadar gula darah & $\begin{array}{l}\text { Ada perbedaan yang signifikan antara } \\
\text { kadar gula darah rata-rata pasien diabetes } \\
\text { tipe } 2 \text { pada kelompok perlakuan dan } \\
\text { kelompok kontrol, dengan nilai } p=0,000 \\
(\mathrm{p}<0,05) \text {. }\end{array}$ \\
\hline 3 & \begin{tabular}{|l|} 
Mindfulness-Based \\
Meditation Versus \\
Progressive Relaxation \\
Meditation: Impact on \\
Chronic Pain in Older \\
Female Patients With \\
Diabetic Neuropathy ${ }^{(10)}$
\end{tabular} & $\begin{array}{|lrr|}\text { Abu Dhabi, } & 105 \\
\text { partisipan } & \text { penelitian } \\
\text { dibagi secara acak } & \text { menjadi } 3 \text { kelompok: } \\
\text { Grup MM } \text { (meditasi } \\
\text { mindfulness), Grup CM } \\
\text { (kontrol meditasi), dan } \\
\text { Grup PM (meditasi } \\
\text { relaksasi progresif). } \\
\end{array}$ & $\begin{array}{l}\text { Quasi } \\
\text { experiment }\end{array}$ & \begin{tabular}{|lr} 
Rata-rata persediaan \\
Nyeri Singkat (BPI) \\
dimodifikasi & untuk \\
neuropati r perifer & diabetes rang \\
menyakitkan & (BPI- \\
DPN Q4); & Patient \\
Global Impression \\
of Change (PGIC). \\
\end{tabular} & $\begin{array}{l}\text { Hasil Kedua Grup MM dan PM } \\
\text { mengalami pengurangan signifikan (P } \\
\text { <.05) nyeri harian rata-rata dalam } 24 \text { jam } \\
\text { terakhir pada akhir studi dibandingkan } \\
\text { dengan awal }(28,7 \% \text { dan } 39,7 \% \text {, masing- } \\
\text { masing). }\end{array}$ \\
\hline 4 & $\begin{array}{|lr|}\text { Effects Of Twenty-Four } \\
\text { Move Shadow Boxing } \\
\text { Combined } \\
\text { With Psychosomatic } \\
\text { Relaxation On Depression } \\
\text { And Anxiety In Patients } \\
\text { With Type-2 Diabetes }{ }^{(12)} \\
\end{array}$ & $\begin{array}{|llr|}\text { China, } & 120 & \text { pasien } \\
\text { Diabetes } & \text { Tipe } & 2 \text { dan } \\
\text { gejala depresi } & / \text { cemas } \\
\text { dibagi } & \text { menjadi } \\
\text { kelompok intervensi }(60 \\
\text { pasien) dan } & \text { kelompok } \\
\text { kontrol }(60 \text { pasien). } \\
\end{array}$ & $\begin{array}{l}\text { Quasi } \\
\text { experiment }\end{array}$ & $\begin{array}{l}\text { Self-rating } \\
\text { Depression Scale } \\
\text { (SDS); Self-Rating } \\
\text { Anxiety Scale } \\
\text { (SAS); HbAlc }\end{array}$ & $\begin{array}{l}\text { Perbedaan antara skor depresi dan } \\
\text { kecemasan pada kelompok intervensi } \\
\text { sebelum dan sesudah pengobatan secara } \\
\text { statistik signifikan }(\mathrm{P}<0,001) \text {. }\end{array}$ \\
\hline 5 & $\begin{array}{|lr|}\text { Implementation Of A } \\
\text { Stress } \quad \text { Management } \\
\text { Program In Outpatients } \\
\text { With Type } 2 \text { Diabetes } \\
\text { Mellitus: A Randomized } \\
\text { Controlled Trial }{ }^{(13)} \\
\end{array}$ & 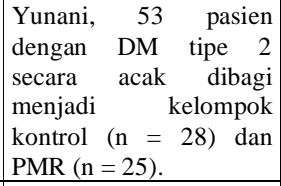 & $\begin{array}{l}\text { Randomized } \\
\text { Controlled } \\
\text { Trial }\end{array}$ & $\begin{array}{l}\text { Perceived stress } \\
\text { score; health locus } \\
\text { of control; HbAlc }\end{array}$ & $\begin{array}{l}\text { Pada kelompok intervensi yang dirasakan } \\
\text { skor stres (PSS) dan HbA1c telah } \\
\text { menurun secara signifikan }(\mathrm{p}>0,05) \text { pada } \\
\text { akhir program. }\end{array}$ \\
\hline 6 & 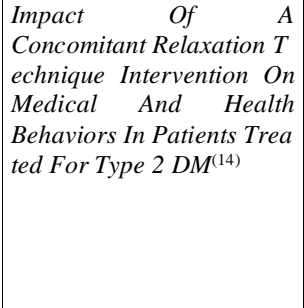 & $\begin{array}{l}\text { Japan, } 24 \text { pasien DM } \\
\text { tipe 2 }\end{array}$ & $\begin{array}{l}\text { Quasi } \\
\text { experiment }\end{array}$ & \begin{tabular}{|lr} 
Perubahan & \\
konsentrasi & amilase \\
saliva; & tekanan \\
darah; & denyut \\
jantung; & tingkat \\
HbAlc; & skala \\
relaksasi; & skala \\
perilaku & koping; \\
pola & kesehatan \\
mental &
\end{tabular} & $\begin{array}{l}\text { Ada perbedaan yang signifikan dalam } \\
\text { indeks fisik (konsentrasi amilase saliva, } \\
\text { tekanan darah, denyut jantung) dan skala } \\
\text { relaksasi antara periode pra-intervensi dan } \\
\text { pasca-intervensi (p <0,05-0,01). Tingkat } \\
\text { HbA1c selama intervensi stabil dalam } \\
\text { kisaran yang lebih baik dibandingkan } \\
\text { dengan tahun sebelumnya (p }<0,05-0,01) \text {. }\end{array}$ \\
\hline 7 & $\begin{array}{l}\text { The Effect of Relaxation } \\
\text { on Blood Sugar and Blood } \\
\text { Pressure Changes of } \\
\text { Women with Gestational } \\
\text { Diabetes: a Randomized } \\
\text { Control Trial }{ }^{(15)}\end{array}$ & $\begin{array}{l}\text { Iran, } 58 \text { pasien dengan } \\
\text { diabetes gestasional } \\
\text { yang dirujuk ke rumah } \\
\text { sakit Hafez, Shiraz, } \\
\text { dipilih melalui simple } \\
\text { random sampling. }\end{array}$ & $\begin{array}{l}\text { Randomized } \\
\text { Controlled } \\
\text { Trial }\end{array}$ & $\begin{array}{lrr}\text { Gula darah } & \text { puasa } \\
\text { dan } & 2 & \text { jam } \\
\text { postprandial; } & \\
\text { tekanan } & \text { darah } \\
\text { sistolik } & \text { dan } \\
\text { diastolik. } & \end{array}$ & $\begin{array}{l}\text { Rata-rata gula darah puasa adalah } 94,79 \\
\text { dan } 103 \mathrm{mg} / \mathrm{dl} \text { pada kelompok intervensi } \\
\text { dan kontrol, masing-masing (P <0,001). } \\
\text { Selain itu, rata-rata } 2 \text { jam postprandial } \\
\text { darah gula adalah } 107 \mathrm{mg} / \mathrm{dl} \text { pada } \\
\text { kelompok intervensi dan } 118 \mathrm{mg} / \mathrm{dl} \text { pada } \\
\text { kelompok kontrol }(\mathrm{P}<0,001) \text {. Selain itu, } \\
\text { rata-rata darah sistolik tekanan adalah } 120 \\
\text { dan } 127 \mathrm{mg} / \mathrm{dl} \text { pada kelompok intervensi } \\
\text { dan kontrol, masing-masing }(\mathrm{P}=0,006) \text {. }\end{array}$ \\
\hline
\end{tabular}

\section{Karakteristik Intervensi}

Terdapat artikel yang tidak memiliki pembanding(14),(15). Penentuan jumlah sample pada penelitian dilakukan dengan cara pasien dikumpulkan kemudian secara acak dibagi menjadi 2 kelompok. Penelitian yang membagi pasien DM menjadi 3 kelompok: Grup MM (meditasi mindfulness), Grup CM (kontrol meditasi), dan Grup PM (meditasi relaksasi progresif) ${ }^{(10)}$. Pasien kelompok perlakuan diberikan latihan progressive muscle relaxation dan mendokumentasi hasilnya. Systematic review ini bertujuan menilai manfaat latihan progressive 
muscle relaxation dibandingkan dengan perawatan biasa. Waktu intervensi (periode) dari studi yang dipilih berkisar antara 3 hari $^{(3)}, 8$ minggu $^{(10),(13)}, 10$ minggu $^{(15)}, 12$ minggu $^{(11)}, 24$ minggu $^{(12)}$ dan 8 bulan $^{(14)}$. Ada 7 artikel yang berisi program latihan progressive muscle relaxation yang meliputi lama latihan, gerakan yang dilakukan selama latihan, intensitas, frekuensi dan prosedur latihan. Prosedur latihan progressive muscle relaxation tidak konsisten, misalnya kelompok otot yang dilakukan, intensitas dan frekuensi latihan.

Tabel 2. Karakteristik progressive muscle relaxation pada pasien diabetes melitus

\begin{tabular}{|c|c|c|c|c|c|}
\hline No & Judul dan Penulis & Lama & Gerakan & $\begin{array}{l}\text { Intensitas \& } \\
\text { Frekuensi }\end{array}$ & Prosedur \\
\hline 1 & \begin{tabular}{|l|} 
The effect of \\
progressive muscle \\
relaxation on \\
glycated \\
hemoglobin and \\
health-related \\
quality of life in \\
patients with type 2 \\
diabetes mellitus $^{(11)}$
\end{tabular} & $\begin{array}{l}12 \\
\text { minggu }\end{array}$ & \begin{tabular}{|l|}
16 \\
kelompok \\
otot
\end{tabular} & $\begin{array}{l}\text { Seminggu pada dua } \\
\text { hari berturut-turut } \\
\text { di pagi hari selama } \\
45-60 \text { menit. }\end{array}$ & $\begin{array}{l}\text { Di sesi pertama, perbedaan kelompok otot dalam tubuh, } \\
\text { pernapasan dalam, dan persiapan sebelum berlatih penjelasan } \\
\text { teknik latihan, sementara prosedur ditunjukkan praktisi. } \\
\text { Pada sesi kedua, pasien diminta untuk melakukan prosedur, } \\
\text { sementara para peneliti memberikan umpan balik selama latihan. } \\
\text { Peneliti memastikan bahwa setiap orang mempelajari teknik PMR } \\
\text { Jacobson. Juga, pendidikan pamflet dan CD pelatihan (deskripsi } \\
\text { langkah-langkah PMR) diberikan kepada semua pasien dari } \\
\text { kelompok PMR. Lalu, para pasien diminta berlatih di rumah dua } \\
\text { kali sehari selama 15 menit } 12 \text { minggu. }\end{array}$ \\
\hline 2 & \begin{tabular}{|l|} 
Progressive muscle \\
relaxation \\
Effectiveness of the \\
blood sugar \\
Patients with type 2 \\
diabetes $^{(3)}$
\end{tabular} & 3 hari & \begin{tabular}{|l}
14 \\
kelompok \\
otot
\end{tabular} & $\begin{array}{l}\text { Latihan dilakukan } \\
\text { dengan durasi } 25 \text { - } \\
30 \text { menit. Latihan } \\
\text { dilakukan selama } \\
\text { tiga hari berturut- } \\
\text { turut selama } 6 \text { kali } \\
\text { setiap pagi dan } \\
\text { malam } \\
\end{array}$ & $\begin{array}{l}\text { Setelah pengukuran kadar glukosa darah dengan accu check (pre } \\
\text { test), kelompok perlakuan diberikan intervensi latihan progresif } \\
\text { terapi relaksasi otot dengan durasi } 25 \text { - } 30 \text { menit dalam satu } \\
\text { latihan, gunakan } 14 \text { gerakan tubuh. setelah program pelatihan } \\
\text { selesai, lakukan pengukuran glukosa darah ke-4 dengan cek accu } \\
\text { (post-test). }\end{array}$ \\
\hline 3 & \begin{tabular}{|l|} 
Mindfulness-Based \\
Meditation Versus \\
Progressive \\
Relaxation \\
Meditation: Impact \\
on Chronic Pain in \\
Older Female \\
Patients With \\
Diabetic \\
Neuropathy \\
$10)$
\end{tabular} & $\begin{array}{l}8 \\
\text { minggu }\end{array}$ & $\begin{array}{l}16 \\
\text { kelompok } \\
\text { otot }\end{array}$ & $\begin{array}{l}\text { Latihan dilakukan } 2 \\
\text { kali setiap minggu }\end{array}$ & $\begin{array}{l}\text { Peserta penelitian ditempatkan secara acak menjadi } 3 \text { kelompok } \\
\text { berdasarkan pada rejimen pengobatan mereka: Grup MM } \\
\text { (meditasi mindfulness), Grup CM (meditasi kontrol), dan Grup } \\
\text { PM (relaksasi progresif meditasi). } \\
\text { Grup PM menjalani } 16 \text { sesi relaksasi otot progresif meditasi. Sesi } \\
\text { terdiri dari } 5 \text { menit duduk dengan tenang, } 23 \text { menit relaksasi otot } \\
\text { progresif, dan } 2 \text { hingga } 3 \text { menit bangun. }\end{array}$ \\
\hline 4 & \begin{tabular}{|l|} 
Effects Of Twenty- \\
Four Move Shadow \\
Boxing Combined \\
With Psychosomatic \\
Relaxation On \\
Depression And \\
Anxiety In Patients \\
With Type-2 \\
Diabetes ${ }^{(12)}$
\end{tabular} & \begin{tabular}{|l|}
24 \\
minggu
\end{tabular} & & $\begin{array}{l}\text { Latihan dilakukan } \\
\text { selama 3-5 hari } \\
\text { setiap minggu, dua } \\
\text { kali sehari (pagi dan } \\
\text { sore) dengan durasi } \\
40 \text { menit. }\end{array}$ & $\begin{array}{l}\text { Sebelum intervensi, mereka diberi panduan tindakan oleh pelatih } \\
\text { profesional selama } 3 \text { hari berturut-turut. Materi pengajaran } \\
\text { diberikan kepada pasien untuk menguasai teknik mereka. Selama } \\
\text { intervensi, pasien berlatih Twenty-four Move Shadow Boxing dan } \\
\text { relaksasi psikosomatis selama 3-5 hari setiap minggu, dua kali } \\
\text { sehari (pagi dan sore), bersamaan dengan pemanasan } \\
\text { dan kegiatan pendinginan. }\end{array}$ \\
\hline 5 & \begin{tabular}{|l|} 
Implementation $O f$ \\
A Stress \\
Management \\
Program In \\
Outpatients With \\
Type 2 Diabetes \\
Mellitus: $A$ \\
Randomized \\
Controlled Trial ${ }^{(13)}$ \\
\end{tabular} & $\begin{array}{l}8 \\
\text { minggu }\end{array}$ & & $\begin{array}{l}\text { Latihan dilakukan } \\
\text { dua kali sehari } \\
\text { selama } 8 \text { minggu } \\
\text { dan membuat buku } \\
\text { harian }\end{array}$ & $\begin{array}{l}\text { Pada kelompok perlakuan RB-PMR disediakan oleh CD audio } \\
\text { yang terdiri } 10 \text { menit DB (pernapasan dalam) dan } 15 \text { menit PMR. } \\
\text { Berlatih beberapa latihan dan penjelasan tentang RB-PMR dan } \\
\text { manfaat kesehatan diikuti. }\end{array}$ \\
\hline 6 & \begin{tabular}{|l|} 
Impact Of A \\
Concomitant Relaxa \\
tion Technique \\
Intervention On \\
Medical And Health \\
Behaviors In Patien \\
ts Treated \\
For Type $2 \mathrm{DM}^{(14)}$
\end{tabular} & $\begin{array}{l}8 \text { bulan }( \\
2 \text { bulan } \\
\text { periode } \\
\text { pre- } \\
\text { intervens } \\
\text { i dan } 6 \\
\text { bulan } \\
\text { periode } \\
\text { intervens } \\
\text { i) } \\
\end{array}$ & \begin{tabular}{|l|}
9 \\
kelompok \\
otot
\end{tabular} & $\begin{array}{l}\text { Latihan diberikan } 7 \\
\text { kali selama } 6 \text { bulan }\end{array}$ & $\begin{array}{l}\text { Pengukuran eksperimental dilakukan di ruang pemeriksaan pribadi } \\
\text { di klinik rawat jalan rumah sakit. Saat pertama kali, kedua kelopak } \\
\text { mata tertutup dan kemudian pasien menjadi tenang sambil } \\
\text { mengulangi teknik pernapasan selama sekitar } 1 \text { menit. Selanjutnya } \\
\text { kelompok sembilan otot tegang ((1) kedua lengan, (2) kedua kaki, } \\
\text { (3) kedua paha, (4) daerah gluteal, (5) daerah dada (6) kedua bahu, } \\
\text { (7) dahi (8) glabella (9) mata, rahang dan bibir) sekitar } 5 \text { detik dan } \\
\text { santai (15-20 detik) secara berurutan. Prosedur ini diulangi selama } \\
20 \text { menit sambil mengulangi teknik pernapasan lagi di akhir } \\
\text { prosedur. }\end{array}$ \\
\hline 7 & $\begin{array}{l}\text { The Effect of } \\
\text { Relaxation on } \\
\text { Blood Sugar and } \\
\text { Blood Pressure } \\
\text { Changes of Women } \\
\text { with Gestational } \\
\text { Diabetes: a } \\
\text { Randomized } \\
\end{array}$ & $\begin{array}{l}10 \\
\text { minggu }\end{array}$ & 5 sesi & $\begin{array}{l}\text { latihan relaksasi } \\
\text { dilakukan selama } \\
10 \text { minggu, lima } \\
\text { sesi dengan durasi } \\
45 \text { menit }\end{array}$ & $\begin{array}{l}\text { Sesi pertama : intervensi termasuk pelatihan tentang sifat dan } \\
\text { mekanisme diabetes, menjelaskan sifat stres dan itu efek pada } \\
\text { tubuh, mengidentifikasi stres dalam kehamilan, dan memahami } \\
\text { konsep relaksasi. } \\
\text { Sesi kedua : teknik pernapasan dan posisi tubuh selama relaksasi } \\
\text { diajarkan. } \\
\text { Sesi ketiga : tentang bagaimana mengendurkan otot-otot berbagai } \\
\text { bagian tubuh setelah stres. }\end{array}$ \\
\hline
\end{tabular}




\begin{tabular}{|l|l|l|l|c|l|}
\hline No & Judul dan Penulis & Lama & Gerakan & $\begin{array}{c}\text { Intensitas \& } \\
\text { Frekuensi }\end{array}$ & \multicolumn{1}{c|}{ Prosedur } \\
\hline & Control Trial ${ }^{(15)}$ & & & & $\begin{array}{l}\text { Sesi keempat : tentang relaksasi melalui pengkondisian. } \\
\text { Sesi kelima : pelatihan diferensial relaksasi dan relaksasi bersama } \\
\text { citra mental positif. }\end{array}$ \\
\hline
\end{tabular}

\section{PEMBAHASAN}

Pasien DM rentan mengalami stres dan kecemasan berkaitan dengan perawatan yang harus dijalani dan komplikasi yang ditimbulkannya. Kondisi ini sangat berkaitan dengan perawatan DM yang harus dijalani seperti diet atau pengaturan makan, kontrol gula darah, konsumsi obat, dan latihan jasmani yang harus dilakukan sepanjang hidupnya $^{(16)}$. Keluhan fisik serta komplikasi dari DM membuat pasien merasakan bahwa kesehatan fisik yang mereka alami sedang mengalami penurunan. Kesehatan fisik yang menurun mengakibatkan kualitas hidup mereka menjadi buruk $^{(17)}$. Latihan jasmani adalah salah satu pilar dalam pengelolaan penyakit DM apabila tidak disertai adanya nefropati ${ }^{(1)}$. Latihan jasmani yang dianjurkan pada pasien DM yaitu latihan yang dilakukan secara teratur dengan frekuensi 3 sampai dengan 4 kali dalam seminggu dengan rentang waktu selama kurang lebih 30 menit setiap kali latihan yang sesuai dengan continous, rhythmical, interval, progresive, endurance (CRIPE). Namun latihan juga harus disesuaikan dengan kemampuan pasien agar tidak timbul cedera ${ }^{(18)}$. Latihan jasmani dengan teknik relaksasi yang dapat diterapkan pada pasien DM adalah Progressive Muscle Relaxation (PMR) ${ }^{(7)}$.

Jacobson menjelaskan bahwa PMR dapat memfasilitasi peningkatan metabolisme tubuh, mempercepat pernapasan, ketegangan dan rileksasi otot, keseimbangan tekanan darah sistolik dan diastolik, dan meningkat gelombang otak alfa ${ }^{(5)}$. Gerakan kelompok otot secara progresif harus dilakukan secara berturut-turut agar dapat memunculkan kondisi rileks yang dapat menyebabkan terjadinya perubahan impuls saraf pada jalur aferen ke otak. Perubahan ini menyebabkan perasaan pasien menjadi lebih tenang baik fisik maupun psikologis ditandai dengan berkurangnya denyut jantung serta menurunkan kecepatan metabolisme tubuh dalam hal ini mencegah peningkatan gula darah pada pasien DM. Hipofisis anterior juga inhibisi sehingga ACTH yang menyebabkan sekresi kortisol menurun sehingga proses gluconeogenesis, katabolisme protein dan lemak yang berperan meningkatkan gula darah akan menurun ${ }^{(19)}$.

Latihan PMR terdiri atas tiga sesi dengan tujuan masing-masing. Pada sesi satu bertujuan untuk mengidentifikasikan ketegangan otot-otot yang dirasakan. Pada sesi dua bertujuan menjelaskan prosedur pelaksanaan latihan PMR. Pada sesi ketiga bertujuan mengevaluasi gerakan yang sudah dilakukan. Latihan dilakukan dengan mengencangkan dan melemaskan sekelompok otot yang meliputi tangan dan lengan dominan dan bukan lengan dominan, bisep dominan dan non dominan, dahi, pipi atas dan hidung, pipi bawah dan rahang, leher dan tenggorokan. Dada dengan bahu dan punggung atas, perut, paha dominan dan non dominan, betis dominan dan non dominan dan kaki dominan dan non dominan ${ }^{(20)}$. PMR dapat diajarkan oleh profesional perawatan kesehatan, termasuk psikolog klinis dan perawat, serta ahli hipnoterapis, instruktur yoga, dan praktisi pelengkap lainnya ${ }^{(21)}$. Terapis mendemonstrasikan gerakan 1 sampai dengan 6 yaitu mulai proses kontraksi dan relaksasi otot diiringi tarik nafas dan hembuskan secara perlahan meliputi 1) Gerakan pertama ditujukan untuk otot dahi dan mata, 2) Gerakan kedua ditujukan untuk otot-otot pipi, 3) Gerakan ketiga ditujukan untuk otot-otot sekitar mulut, 4) Gerakan keempat ditujukan untuk otot-otot rahang dan mulut, 5) Gerakan kelima ditujukan untuk otot-otot leher belakang, 6) Gerakan keenam ditujukan untuk otot leher bagian depan. Kemudian terapis meminta klien untuk meredemonstrasikan kembali gerakan 1 sampai dengan 6.

Terapis mendemonstrasikan gerakan 7 sampai dengan 13 yaitu mulai proses kontraksi dan relaksasi otot diiringi tarik nafas dan hembuskan secara perlahan meliputi 7) Gerakan ketujuh ditujukan untuk otot-otot bahu, 8) Gerakan kedelapan ditujukan untuk otot tangan, 9) Gerakan kesembilan ditujukan untuk otot tangan bagian belakang, 10) Gerakan kesepuluh ditujukan untuk otot-otot lengan atau biseps, 11) Gerakan sebelas ditujukan untuk otot-otot punggung, 12) Gerakan dua belas ditujukan untuk otot-otot perut, 13) Gerakan tigabelas ditujukan untuk otot-otot betis. Kemudian terapis meminta klien mendemonstrasikan kembali gerakan 7 sampai dengan $13^{(20)}$.

Beberapa hal yang perlu diperhatikan selama latihan di antaranya pasien yang mengalami distres emosional selama melakukan PMR dianjurkan menghentikan latihan dan mengkonsultasikannya kepada perawat/dokter mengenai (5). Adapun kontraindikasi dari latihan ini diantaranya terjadinya cedera akut atau ketidaknyamanan muskuloskeletal, infeksi atau inflamasi, dan penyakit jantung berat atau akut serta tidak dilakukan pada sisi otot yang sakit ${ }^{(20)}$.

Pasien yang mengalami stres secara fisik akan mengalami ketegangan otot dan secara psikologis akan merasa cemas $^{(22)}$. PMR merupakan teknik relaksasi dan kemampuan pengelolaan diri yang mampu mengurangi ketegangan otot, stress, menurunkan tekanan darah, meningkatkan toleransi terhadap aktivitas sehari-hari, meningkatkan imunitas sehingga kualitas hidup pasien DM meningkat ${ }^{(23)}$. Latihan ini bermanfaat untuk mengurangi konsumsi oksigen tubuh, laju metabolisme tubuh, laju pernapasan, ketegangan otot, kontraksi ventricular prematur dan tekanan darah sistolik serta gelombang alpha otak serta dapat meningkatkan beta endorphin dan berfungsi meningkatkan imun seluler. Relaksasi dapat digunakan sebagai keterampilan koping yang aktif jika digunakan untuk mengatasi kecemasan ${ }^{(24)}$. Manfaat gerakan dari latihan PMR akan terlihat apabila dilakukan secara teratur. Pasien akan menjadi lebih mudah untuk memusatkan pikiran dan kondisi rileks akan lebih cepat tercapai. Kondisi ini akan membantu tercapainya kestabilan kerja kelenjar adrenal untuk memproduksi hormon penenang yang akan berdampak pada penurunan stres ${ }^{(25)}$. Jika pasien tidak mampu memusatkan pikiran dalam melakukan latihan ini, hal ini menyebabkan hasil yang maksimal terhadap penurunan kadar 
glukosa darah. Latihan ini mudah di pelajari dan di lakukan dirumah sehingga memungkinkan pasien dan keluarga untuk melakukannya serta tidak membutuhkan biaya yang mahal ${ }^{(26)}$.

\section{KESIMPULAN}

Systematic review ini menunjukkan bahwa progressive PMR berpengaruh pada pasien DM, yang dapat membuat kondisi tubuh menjadi rileks sehingga mengurangi ketegangan otot, stress, tekanan darah, meningkatkan toleransi terhadap aktivitas sehari-hari sehingga kualitas hidup pasien meningkat. Relaksasi juga dapat digunakan sebagai keterampilan koping yang efektif untuk mengatasi respon stress akibat keluhan yang ditimbulkan dari komplikasi DM. Latihan ini merupakan salah satu bentuk mind-body therapy yang dapat diterapkan di Rumah Sakit sebagai pendamping terapi konvensional medis. Namun, PMR hanya dapat diajarkan oleh oleh profesional perawatan kesehatan, diantaranya psikolog klinis dan perawat,ahli hipnoterapis, instruktur yoga, dan praktisi pelengkap lainnya. Rekomendasi untuk penelitian selanjutnya adalah agar dapat melihat pengaruh dari PMR dikombinasikan dengan teknik relaksasi lainnya.

\section{DAFTAR PUSTAKA}

1. PERKENI P. Konsensus Pengelolaan dan Pencegahan Diabetes Melitus Tipe 2 di Indonesia. 2015.

2. Smeltzer SC, Bare BG. Keperawatan Medikal Bedah. 10th ed. English: Lippincott Williams \&Wilkins; 2004.

3. Avianti N, Desmaniarti Z, Rumahorbo H. Progressive Muscle Relaxation Effectiveness of the Blood Sugar Patients with Type 2 Diabetes. Sci Res Publ. 2016;(March):248-54.

4. Hilliard ME, Yi-frazier JP, Hessler D, Butler AM, Anderson BJ, Jaser S. Stress and A1c Among People with Diabetes Across the Lifespan. Curr Diab Rep [Internet]. 2016; Available from: http://dx.doi.org/10.1007/s11892-016-0761-3

5. Ruth Lindquist, Snyder M, Tracy MF. Complementary \& Alternative Therapies in Nursing Seventh Edition. Springer Publishing Company, LLC; 2014.

6. Hasaini A. Efektifitas Progressive Muscles Relaxation (PMR) Terhadap Kadar Glukosa Darah Pada Kelompok Penderita Diabetes Mellitus Tipe 2 Di Puskesmas Martapura. Caring. 2015;2:16-27.

7. Ghezeljeh TN, Kohandany M, Oskouei FH, Malek M. The Effect Of Progressive Muscle Relaxation On Glycated Hemoglobin And Health-Related Quality Of Life In Patients With Type 2 Diabetes Mellitus. Elsevier. 2017;33:142-8.

8. Simanjuntak GV, Simamora M. Pengaruh Latihan Relaksasi Otot Progresif Terhadap Kadar Gula Darah Dan Ankle Brachial Index Pada Pasien Diabetes Melitus Tipe II. Idea Nurs J. 2017;VIII(1).

9. Ilmi ZM, Dewi EI, Rasni H. Pengaruh Relaksasi Otot Progresif Terhadap Tingkat Stres Narapidana Wanita di Lapas Kelas IIA Jember. 2017;5(3):497-504.

10. Hussain N, Said ASA. Mindfulness-Based Meditation Versus Progressive Relaxation Meditation: Impact on Chronic Pain in Older Female Patients With Diabetic Neuropathy. J Evidence-Based Integr Med. 2019;24:1-8.

11. Ghezeljeh TN, Kohandany M, Oskouei FH, Malek M. The Effect of Progressive Muscle Relaxation on Glycated Hemoglobin and Health-related Quality of Life in Patients with Type 2 Diabetes Mellitus. Elsevier. 2017;33:142-8.

12. Zheng Y, Zhou Y, Lai Q. Effects Of Twenty-Four Move Shadow Boxing Combined With Psychosomatic Relaxation On Depression And Anxiety In Patients With Type-2 Diabetes. Psychiatr Danub. 2015;27(2):174-9.

13. Koloverou E, Tentolouris N, Bakoula C, Darviri C, Chrousos G. Implementation of A Stress Management Program in Outpatients with Type 2 Diabetes Mellitus: A Randomized Controlled Trial. Hormones. 2014;13(4):509-18.

14. Katada Y, Koitabashi K, Tomono S, Oka M. Impact of a Concomitant Relaxation Technique Intervention on Medical and Health Behaviors in Patients Treated for Type 2 Diabetes Mellitus. Kitakanto Med J. 2014;135-48.

15. Kaviani M, Bahoosh N, Azima S, Asadi N, Sharif F, Sayadi M. The Effect of Relaxation on Blood Sugar and Blood Pressure Changes of Women with Gestational Diabetes: a Randomized Control Trial. Iran J Diabetes Obes. 2014;6(1).

16. Shahab A. Buku Ajar Ilmu Penyakit Dalam. Jilid 3 Ed. Jakarta: Departemen Ilmu Penyakit Dalam Fakultas Kedokteran Universitas Indonesia; 2006.

17. Pagita DT, M RII, L PR. Hubungan Gangguan Depresi dengan Kualitas Hidup Pasien Diabetes Mellitus Tipe 2 di Poliklinik Endokrin Rumah Sakit Cipto Mangunkusumo. J Indon Med Assoc. 2016; Volume 66:465-72.

18. Fatimah RN. Diabetes Melitus Tipe 2. J Major. 2015;4:93-101.

19. Smeltzer SC, Bare BG. Buku Ajar Keperawatan Medikal Bedah. Edisi 8. Waluyo A, editor. Jakarta: EGC; 2002.

20. Supriati L, Keliat BA, Alini, Wardani IY, Tobing DL. Modul Progressive Muscle Relaxation (PMR). Jakarta: Workshop Keperawatan Jiwa ke-IX, Depok. 25 Agustus 2015; 2012.

21. Nuwa MS, Kusnanto K, Utami S. Modul Kombinasi Terapi Progressive Muscle Relaxation Dengan Spiritual Guided Imagery And Music ( Panduan Buat Perawat ). Surabaya: Fakultas Keperawatan Universitas Airlangga; 2018.

22. Safitri W, Putriningrum R. Pengaruh Terapi Relaksasi Progresif Terhadap Kadar Gula Darah Pasien Diabetes Mellitus Tipe 2. PROFESI (Profesional Islam Media Publ Penelit. 2019;16(2):47-54.

23. Smeltzer SC, Bare BG. Buku Ajar Keperawatan Medikal-Bedah Brunner \& Suddarth. Vol. 2. Jakarta: EGC; 2008.

24. Jacobson. Progressive Muscle Relaxation. University of Chicago Press. 1938;

25. Ridha Hidayati. Pengaruh Progressive Muscle Relaxation Terhadap Gula Darah Pada Pasien Diabetes Mellitus Tipe 2 Di Panti Sosial Tresna Werda Sabai Nan Aluih Sicincin Tahun 2016. Menara Ilmu. 2018;XII(4):85-93.

26. Astuti P. Teknik Progressive Muscle Relaxation Mempengaruhi Kadar Glukosa Darah Penderita Diabetes Melitus Tipe 2. J Ilm Kesehat. 2014;7:114-21. 